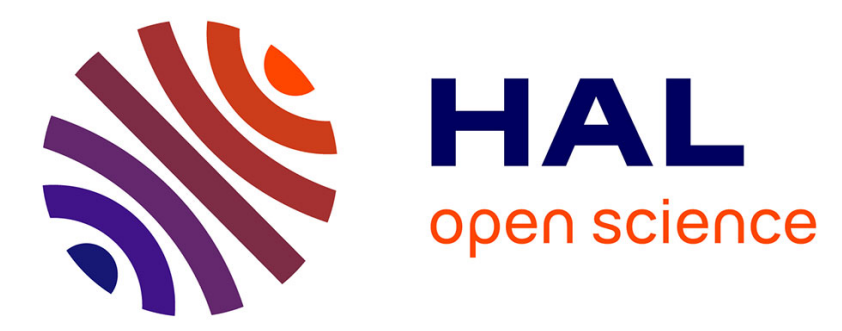

\title{
Unsteady Pressure and Velocity Measurements in 5x5 Rods Bundle Using Grids With and Without Mixing Vanes
}

F. Moreno, S. Bantiche, F. Bazin, T. Lohez, D. Picard, S. Testaniere, Lionel Rossi

\section{To cite this version:}

F. Moreno, S. Bantiche, F. Bazin, T. Lohez, D. Picard, et al.. Unsteady Pressure and Velocity Measurements in 5x5 Rods Bundle Using Grids With and Without Mixing Vanes. NUTHOS-12 12th International Topical Meeting on Nuclear Reactor Thermal-Hydraulics, Operation and Safety, Apr 2018, Qingdao, China. cea-02338866

\section{HAL Id: cea-02338866 https://hal-cea.archives-ouvertes.fr/cea-02338866}

Submitted on 21 Feb 2020

HAL is a multi-disciplinary open access archive for the deposit and dissemination of scientific research documents, whether they are published or not. The documents may come from teaching and research institutions in France or abroad, or from public or private research centers.
L'archive ouverte pluridisciplinaire HAL, est destinée au dépôt et à la diffusion de documents scientifiques de niveau recherche, publiés ou non, émanant des établissements d'enseignement et de recherche français ou étrangers, des laboratoires publics ou privés. 


\title{
Unsteady Pressure and Velocity Measurements in 5x5 Rods Bundle Using Grids With and Without Mixing Vanes (full text)
}

\author{
Moreno F., Bantiche S., Bazin F., Lohez T., Picard D., Testaniere S., Rossi L. \\ CEA, Cadarache, DEN/DTN/STCP/LHC, 13115 Saint-Paul-lez-Durance FRANCE \\ Corresponding Address \\ lionel.rossi@cea.fr
}

\begin{abstract}
The vibration of rods is of prime importance to estimate their wearing due to the frictions with grids' elements. To predict this wearing, the forces exerted on the rods need to be identified and quantified. Pressure fluctuations are explored using an instrumented rod centred within a $5 \times 5$ rods bundle. Two configurations of spacer-grids are used: with and without mixing vanes respectively noted WMV and NMV. The position of the measurement point is rotated over $360^{\circ}$ and its distance from the grids is varied from $0.5 \mathrm{D}_{\mathrm{h}}$ to $20 \mathrm{D}_{\mathrm{h}}$. The results show the non-homogeneity of the azimuthal distribution of the pressure fluctuations in the near wake of the spacer-grids for both configurations. The return to a homogeneous azimuthal distribution of the pressure fluctuations is faster without mixing vanes than with mixing vanes. The intensities of the pressure fluctuations are (in average) higher for WMV than for NMV: higher by $13 \%$ and $136 \%$ respectively at distances $0.5 \mathrm{D}_{\mathrm{h}}$ and $20 \mathrm{D}_{\mathrm{h}}$ from the grids. Power law approximations show decreases of $\left\langle P_{r m s}^{\prime}\right\rangle_{\theta}$ like $\left(y / D_{h}\right)^{-0.46}$ and $\left(y / D_{h}\right)^{-0.68}$ respectively for the configurations WMV and NMV. The profiles of mean velocity and velocity fluctuations are explored around the instrumented rod using LDV. Results show oscillation of the profiles and a damping with the distance from the grids. Power law approximations show decreases of $\left\langle v_{r m s}^{\prime}\right\rangle_{\mathcal{P}_{s q}} / V_{\text {flow }}$ like $\left(y / D_{h}\right)^{-0.38}$ and $\left(y / D_{h}\right)^{-0.46}$ respectively for WMV and NMV. Between $2 \mathrm{D}_{\mathrm{h}}$ and $15 \mathrm{D}_{\mathrm{h}}$, the dimensionless ratio of "pressure fluctuations to velocity fluctuations" $\left\langle P_{r m s}^{\prime}\right\rangle_{\theta} / \frac{1}{2} \rho\left\langle v_{r m s}^{\prime}{ }^{2}\right\rangle_{\mathcal{P}_{s q}}$ is found to increase by $70 \%$ and $100 \%$ respectively for the configurations NMV and WMV. This increase demonstrated by the combination of pressure and velocity measurements further reveals the complexity of the turbulent flow in the wake of spacer-grids.
\end{abstract}

\section{KEYWORDS}

\section{CALIFS, PRESSURE, VELOCITY, SPACER GRIDS, MIXING VANES}

\section{INTRODUCTION}

The vibration of rods is of prime importance to estimate their wearing due to frictions with grids' elements. To predict this wearing, the forces exerted on the rods need to be identified and quantified. To this aim, an experimental study tailored for the validation of CFD simulations is performed with the support of the "FUEL ASSEMBLY Project" (AREVA, CEA, EDF). In addition, it is expected that the combination of such refined experiments and CFD simulations will support the characterisation of the hydraulic performance of the grids.

Previous works addressing the flows within rods bundle in the near wake of spacer-grids include research using PWR spacer-grids, e.g. [1], and analytical spacer-grids, e.g. [2, 3, 4, 5]. Here the experiments are performed with analytical spacer-grids.

The experiments are performed with the rig CALIFS which is a water experimental rig (low-pressure, $20^{\circ} \mathrm{C}$ ) dedicated to the study of turbulent flows within rods bundle. The experiments are performed using 
a $5 \times 5$ rods bundle. Two sets of different grids, with and without mixing vanes, are used to mount the rods bundle.

This manuscript focuses on Reynolds number 66000 where refined pressure and velocity measurements are performed. The experimental rig and measurements are described before discussing results.

\section{EXPERIMENTAL RIG AND MEASUREMENTS}

\subsection{DESCRIPTION OF THE EXPERIMENTAL RIG}

(a)

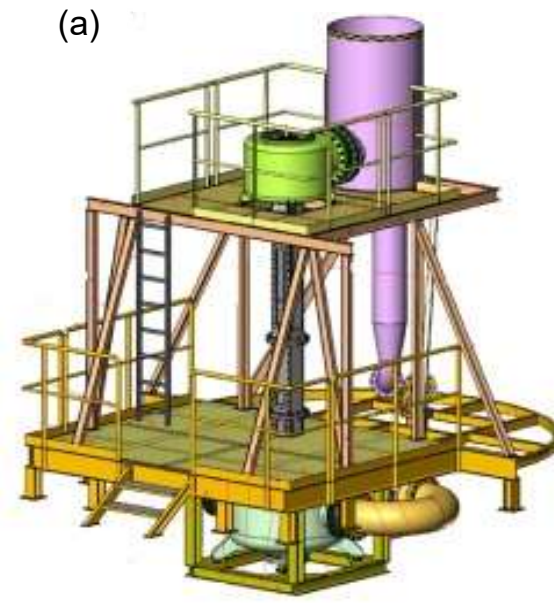

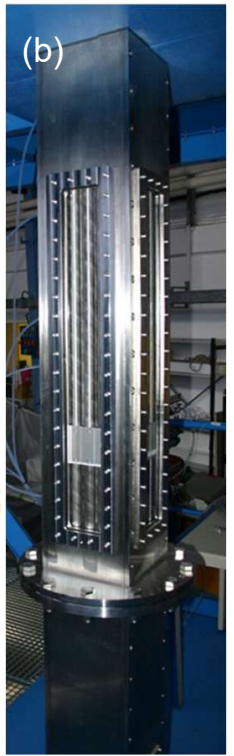

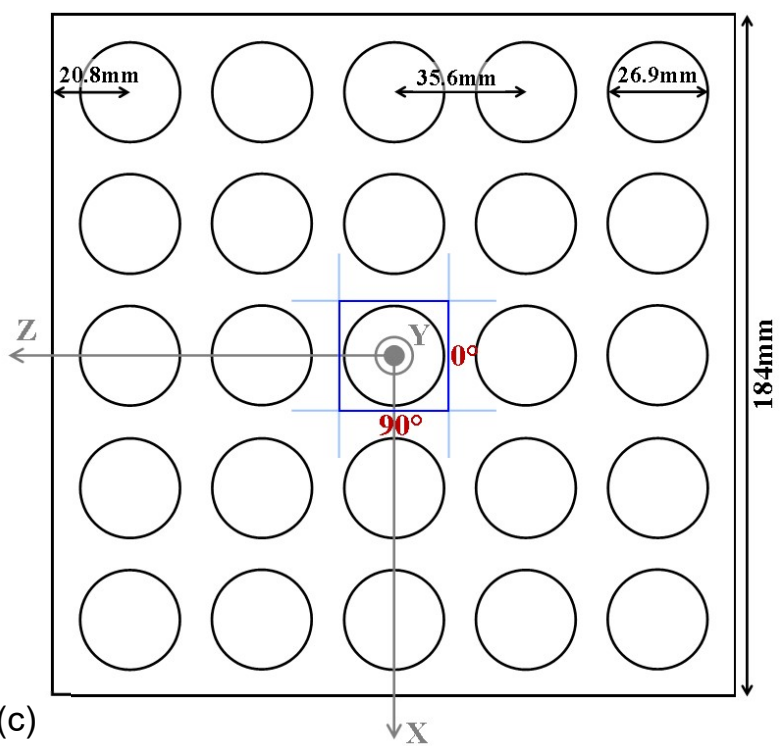

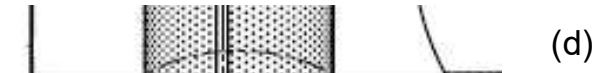

(d)

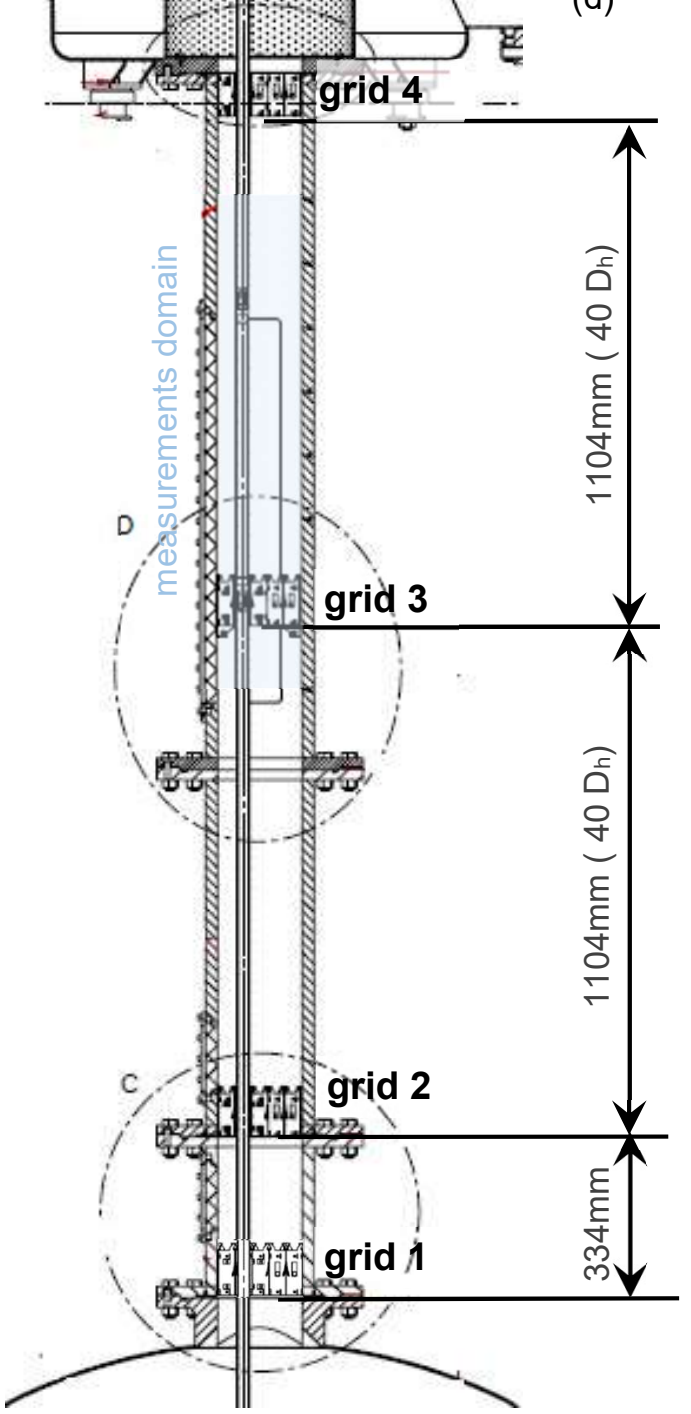

Fig. 1 (a) 3D illustration of the rig CALIFS 5x5; (b) photo of the test section with the $5 \times 5$ rods bundle and grid without mixing vanes; (c) schematic of flow cross-section with the rods bundle. The central (blue) square shows the perimeter $\mathcal{P}_{s q}$ and the central segments (light blue) the LDV measurements lines of $2 D_{h}$ length. The reference position $0^{\circ}$ and $90^{\circ}$ for the pressure measurements are also indicated close to the central rod; (d) schematic with the positions of the grids along the test-section.

CALIFS $5 \times 5$ is a water rig working within the ranges $0-400 \mathrm{~m}^{3} / \mathrm{h}, 10^{\circ}-70^{\circ} \mathrm{C}, 0-10 \mathrm{bar}$. Fig. 1 a gives a $3 \mathrm{D}$ schematic of CALIFS 5x5 and Fig. 1b shows a photo of the test section. The length of the test section is about $2.5 \mathrm{~m}$. The flow cross section is a square of $184 \mathrm{~mm}$ side. A $5 \times 5$ rods bundle, using rods of diameter 
$\mathrm{D}_{\mathrm{rod}}=26.9 \mathrm{~mm}$, is placed within the test section using four spacer-grids. The hydraulic diameter, noted $\mathrm{D}_{\mathrm{h}}$, is $27.7 \mathrm{~mm}$ and is used as the reference length scale.

The geometry of the test section and the distribution of these grids are illustrated in Fig. 1c and Fig. 1d. The grids number 1 and 4 are without mixing vanes. Both grids 2 and 3 are without or with mixing vanes for the cases respectively noted NMV and WMV for No Mixing Vanes and With Mixing Vanes.

Fig. 2 illustrates the grids with and without mixing vanes. The grids are made with $1.2 \mathrm{~mm}$ thick plates of stainless steel 304L. The height of the plates is $93 \mathrm{~mm}$ they are assembled perpendicularly to design a mesh with 25 cells. Within each cell, the rods are sustained radially using dimples and springs-blades. The dimples are made of TEFLON and the springs-blades are made with $1 \mathrm{~mm}$ thick blades of stainless steel $301 \mathrm{~T} 4$.

(a)
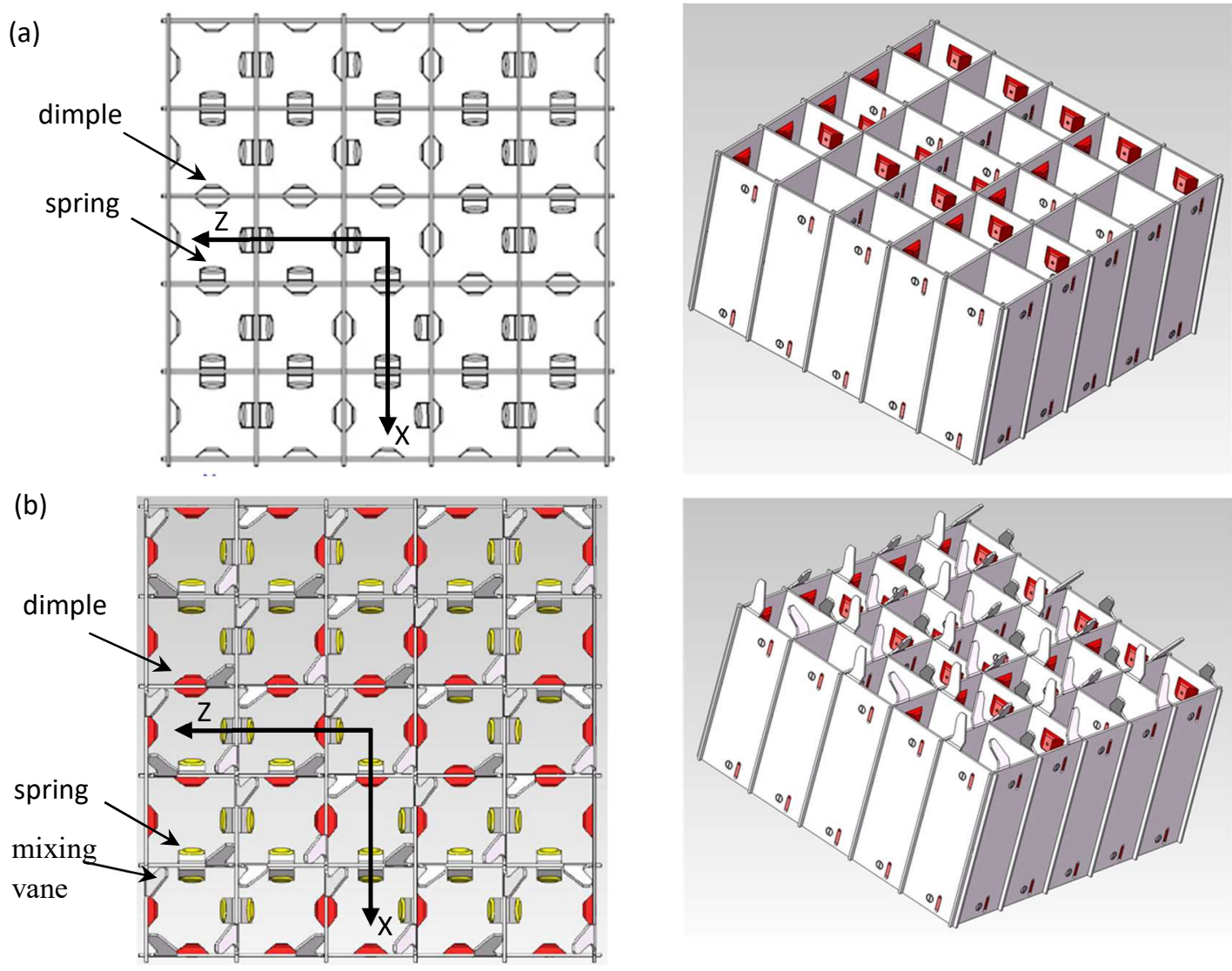

Fig. 2 (a) top row, schematics of the grids without mixing vanes; (b) bottom row, schematics of the grid with mixing vanes

The origin of the coordinates is set as the centre of the central rod at the exit of the grids. $\boldsymbol{y}$ is the vertical direction and $\boldsymbol{x}$ and $\boldsymbol{z}$ are horizontal as illustrated in Fig. 1c.

Experiments are performed with a flow rate velocity, noted $V_{\text {flow }}$, of $2.4 \mathrm{~m} / \mathrm{s}$ and a flow temperature about $20^{\circ} \mathrm{C}$. The Reynolds number, $R e_{D_{h}}$, of the experiments is then about 66000 .

\subsection{PRESSURE MEASUREMENTS}

Pressure drops and unsteady local pressure measurements are performed. Local pressure measurements are realised by instrumenting the central rod of the $5 \times 5$ rods bundle. The distribution of pressure around the rod circumference is obtained by turning the instrumented rod: increment of $10^{\circ}$ are performed over $360^{\circ}$. As illustrated in Fig. 1c, the angular positions, noted $\theta$, are referred clockwise. The $0^{\circ}$ and $90^{\circ}$ correspond respectively to the measurement point positions $\left(\mathrm{z} / \mathrm{D}_{\mathrm{h}}=-0.97, \mathrm{x} / \mathrm{D}_{\mathrm{h}}=0\right)$ and $\left(\mathrm{z} / \mathrm{D}_{\mathrm{h}}=0\right.$, $\left.\mathrm{x} / \mathrm{D}_{\mathrm{h}}=0.97\right)$. The pressure distribution is measured at various longitudinal positions from the grid by translating the instrumented rod: $0.5 \mathrm{D}_{\mathrm{h}}, 1 \mathrm{D}_{\mathrm{h}}, 2 \mathrm{D}_{\mathrm{h}}, 3 \mathrm{D}_{\mathrm{h}}, 4 \mathrm{D}_{\mathrm{h}}, 5 \mathrm{D}_{\mathrm{h}}, 10 \mathrm{D}_{\mathrm{h}}, 15 \mathrm{D}_{\mathrm{h}}$ and $20 \mathrm{D}_{\mathrm{h}}$. 
Two pressure devices ${ }^{1}$ are used. For the first campaign (grid without mixing vanes, NMV) a pressure sensors is mounted on a cavity within the rod with a $2 \mathrm{~mm}$ diameter pipe linking the cavity to the flow [6]. For the measurements' accuracy, the whole pressure device (including sensor, cavity and $2 \mathrm{~mm}$ pipe) is calibrated. For the second campaign (grids with mixing vanes, WMV), a smaller pressure sensor of diameter $1.9 \mathrm{~mm}$ is mounted flush to the rod so as to be in contact with the flow. It can be noted that the diameter of the last sensor (or the hole) is about 44 times smaller than the rod's perimeter.

Each local pressure measurement is performed during $20 \mathrm{~s}$ at $1600 \mathrm{~Hz}$ using a $400 \mathrm{~Hz}$ low pass analogue filter. The uncertainties of the vertical and angular positions of the measurements points are respectively $\pm 1 \mathrm{~mm}$ and $\pm 1^{\circ}$.

\subsection{VELOCITY MEASUREMENTS}

The velocity measurements are performed using LDV (Laser Doppler Velocimetry) and translating the measurement point. The first point is set at $1.33 \mathrm{~mm}$ from the wall and consecutive points are $1.33 \mathrm{~mm}$ spaced. The largest length of the measurement volume is about $0.94 \mathrm{~mm}$. The LDV acquisition rate depends on the rate of the particles ( $4 \mu \mathrm{m}$ NYLON beads) crossing the measurement volume. The LDV statistics rely on 10000 valid events for each measurements points. The uncertainty on the position of the measurement volume is about $\pm 0.5 \mathrm{~mm}$ whilst the displacement uncertainty is of the order of $0.01 \mathrm{~mm}$. On Fig. 1c, the light blue lines (combined with the blue square) show the segments on which the LDV measurements are performed and discussed in this manuscript. These segments correspond to $x / D_{h}=$ \pm 0.54 for $-1 \leq z / D_{h} \leq 1$ and $z / D_{h}= \pm 0.54$ for $-1 \leq x / D_{h} \leq 1$.

\section{RESULTS AND DISCUSSIONS}

The Fig. 3 gives the azimuthal distributions of the root mean square (rms) of the pressure fluctuations, noted $\mathrm{P}_{\mathrm{rms}}^{\prime}$, measured for the configurations with and without mixing vanes at different distances from the grids.

For $y / D_{h} \geq 1, \mathrm{P}_{\text {rms }}^{\prime}$ is larger for the configuration with mixing vanes than for the configuration without. Moreover, for $y / D_{h} \geq 5$ the pressure fluctuations are about 2 times higher for the configuration WMV than for NMV. At the vicinity of the grid, i.e. $y / D_{h} \leq 2$, the distributions of $\mathrm{P}_{\mathrm{rms}}^{\prime}$ are non-homogeneous with $\theta$. Extrema of pressure fluctuations can be attributed to the effect of the dimples, spring-blades, and mixing vanes. For $y / D_{h} \geq 2$, the pressure fluctuations of the flow evolve faster toward a quasi-homogeneous distribution for the configuration without mixing vanes than for the configuration with mixing vanes. In fact, the distribution of the pressure fluctuations is quasihomogeneous for $y / D_{h} \geq 5$ for the configuration without mixing vanes whilst such homogeneity can still be discussed at $y / D_{h}=20$ for the configuration with mixing vanes.

The average over $\theta$ of $P_{r m s}^{\prime}$, noted $\left\langle P_{r m s}^{\prime}\right\rangle_{\theta}$, decreases with $y / D_{h}$. Fig. 4 gives $\left\langle P_{r m s}^{\prime}\right\rangle_{\theta}$ versus $y / D_{h}$ and highlights two power law trends $\sim\left(y / D_{h}\right)^{-0.46}$ and $\sim\left(y / D_{h}\right)^{-0.68}$ respectively for the configurations WMV and NMV. Between $y / D_{h}=0.5$ and $y / D_{h}=20$, so within $20 \mathrm{D}_{\mathrm{h}}$, the values of $\left\langle P_{r m s}^{\prime}\right\rangle_{\theta}$ are divided by about 10 and 5 respectively for the NMV and WMV configurations.

To investigate the frequency domain of the pressure fluctuations the energy spectra of the temporal signal of the pressure fluctuations, noted $\mathfrak{E}\left(k^{*}\right)$, where $k^{*}=f D_{h} / V_{\text {flow }}$, is computed and made dimensionless using the total energy $\mathfrak{E}_{\text {total }}$ so as $\sum \mathfrak{E}\left(k^{*}\right) d k^{*} / \mathfrak{E}_{\text {total }}=1$.

Fig. 5 provides the dimensionless energy spectra averaged over $\theta,\left\langle\mathfrak{E}\left(k^{*}\right)\right\rangle_{\theta} / \mathfrak{E}_{t o t a l}$, for the distances from the grid $0.5 \mathrm{D}_{\mathrm{h}}, 1 \mathrm{D}_{\mathrm{h}}, 2 \mathrm{D}_{\mathrm{h}}, 3 \mathrm{D}_{\mathrm{h}}, 4 \mathrm{D}_{\mathrm{h}}, 5 \mathrm{D}_{\mathrm{h}}, 10 \mathrm{D}_{\mathrm{h}}, 15 \mathrm{D}_{\mathrm{h}}, 20 \mathrm{D}_{\mathrm{h}}$ and the two configurations NMW and WMV. For all distances, the WMV configuration shows more energy at large scales, i.e. $k^{*} \leq 0.5$, than the NMV configuration. At $0.5 \mathrm{D}_{\mathrm{h}}$ both energy spectra present a similar peak around $k^{*}=0.8$. In addition, for the configuration with mixing vanes a damping of the intensity of the peak around $k^{*}=$ 0.8 is observed whilst for the configuration without mixing vanes this peak persists from $0.5 \mathrm{D}_{\mathrm{h}}$ to $20 \mathrm{D}_{\mathrm{h}}$.

\footnotetext{
1 Both pressure transducers are amenable to perform at frequencies higher than $10 \mathrm{kHz}$.
} 
Abstract No: 188 oral presentation
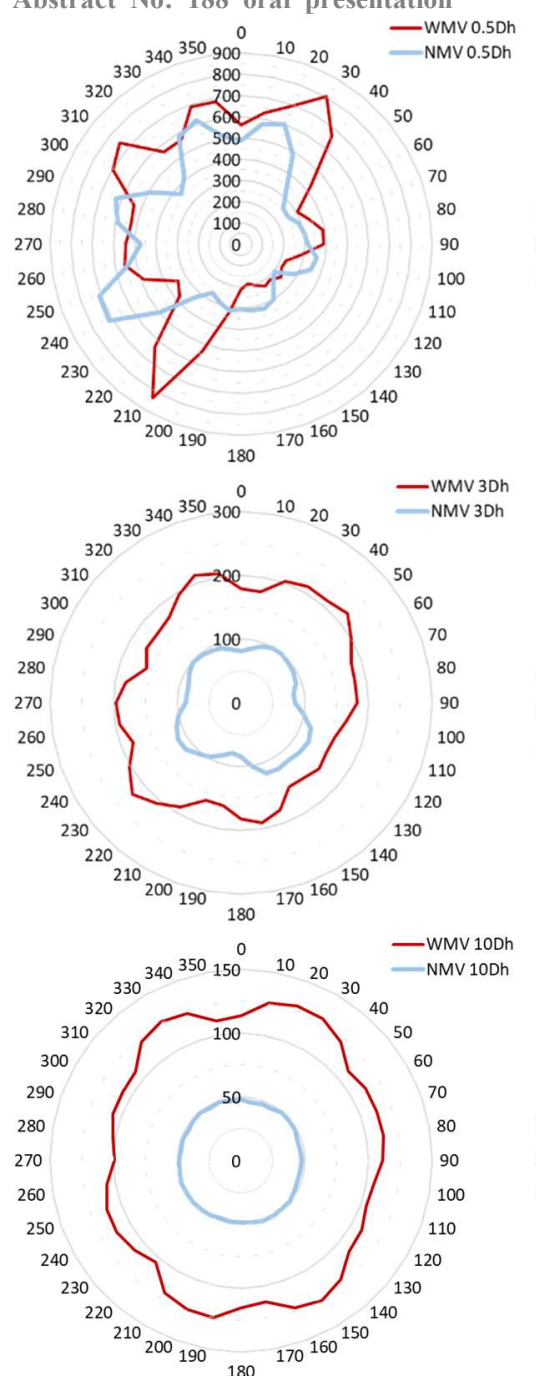
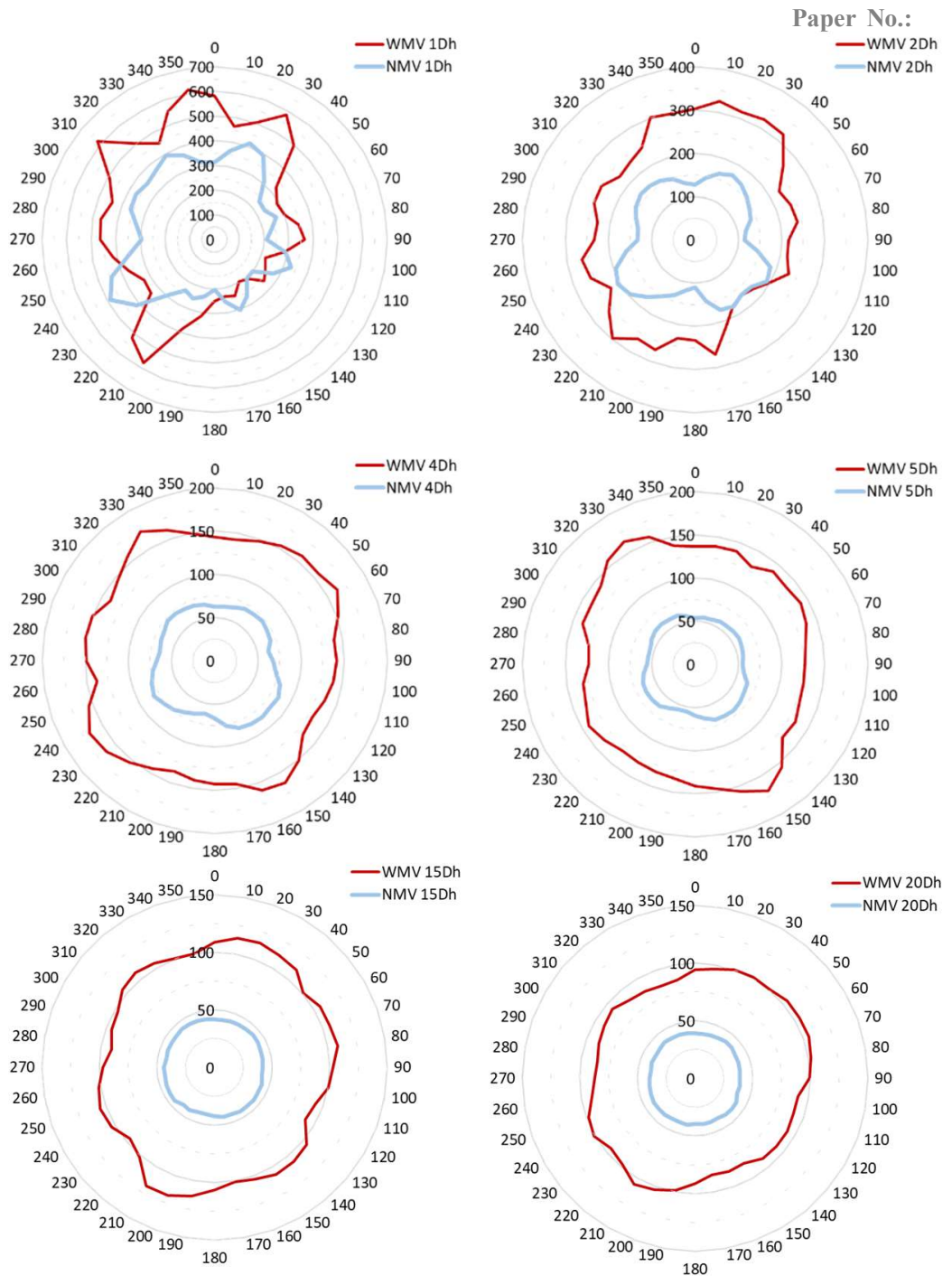

Fig. 3 azimuthal distributions of the rms of the pressure fluctuations $P_{r m s}^{\prime}$ [in Pa] for the cases of grids with mixing vanes (WMV) and without mixing vanes (NMV) for different vertical distances from the grids, i.e. $0.5 \mathrm{D}_{\mathrm{h}}, 1 \mathrm{D}_{\mathrm{h}}, 2 \mathrm{D}_{\mathrm{h}}, 3 \mathrm{D}_{\mathrm{h}}, 4 \mathrm{D}_{\mathrm{h}}, 5 \mathrm{D}_{\mathrm{h}}, 10 \mathrm{D}_{\mathrm{h}}, 15 \mathrm{D}_{\mathrm{h}}$ and $20 \mathrm{D}_{\mathrm{h}}$.

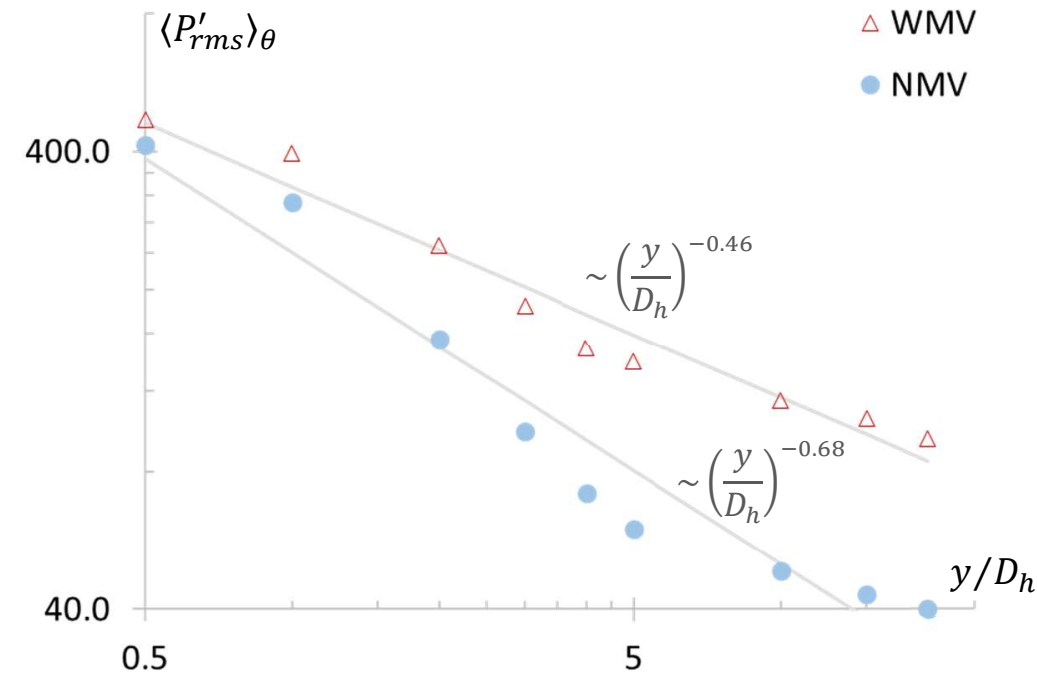

Fig. 4 azimuthal average of the rms of the pressure fluctuations $\left\langle P_{r m s}^{\prime}\right\rangle_{\theta}$ [in Pa] for the cases of grids with mixing vanes (WMV) and without mixing vanes (NMV) versus the vertical distance $y / D_{h}$ from the grids. Grey lines indicate power law trends. 


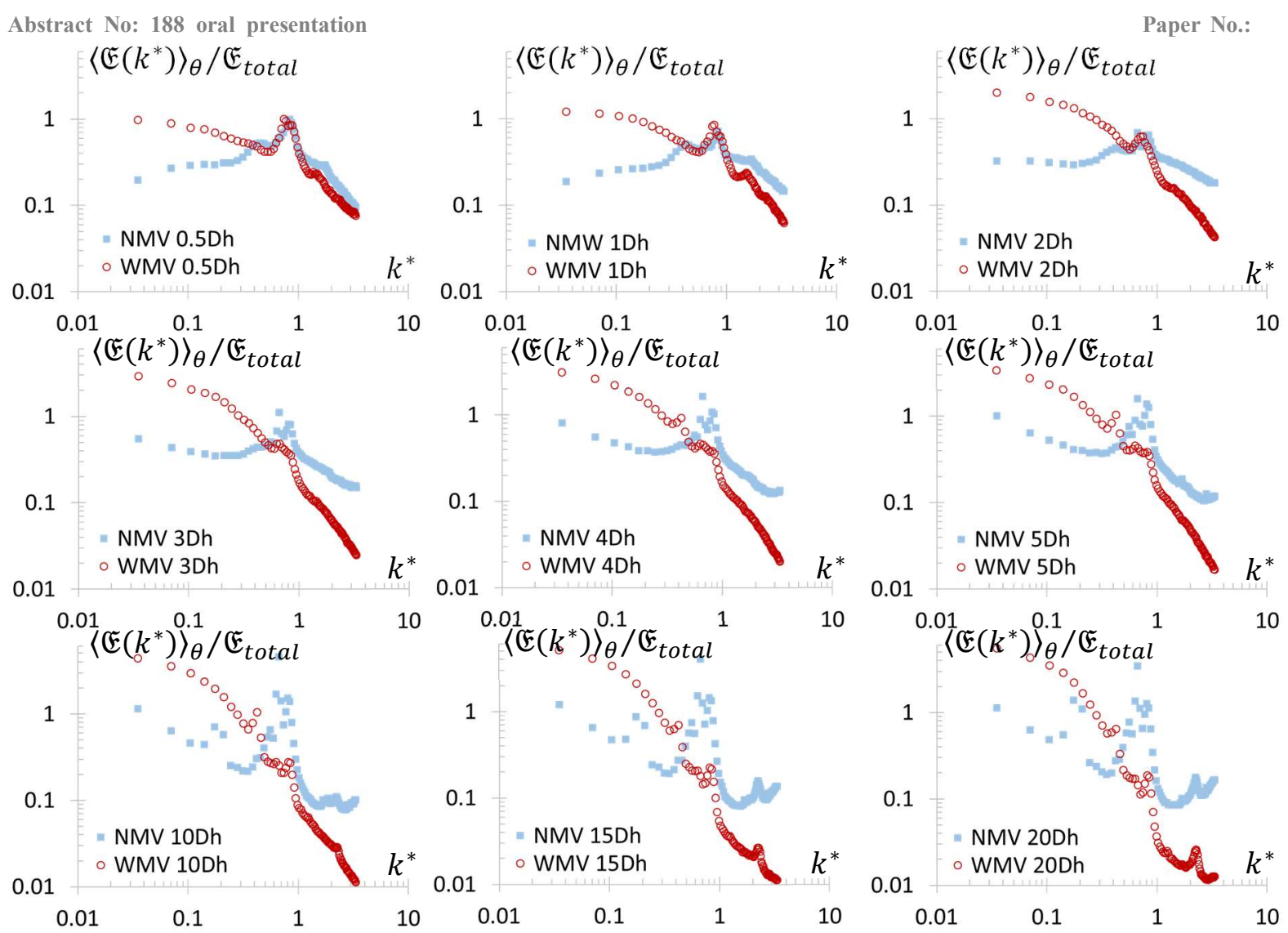

Fig. 5 azimuthal average of the reduced energy spectra of the pressure fluctuations $\left\langle\mathfrak{E}\left(k^{*}\right)\right\rangle_{\theta} / \mathfrak{E}_{\text {total }}$ for the cases of grids with mixing vanes (WMV) and without mixing vanes (NMV) for different vertical distances from the grids, i.e. $0.5 \mathrm{D}_{\mathrm{h}}, 1 \mathrm{D}_{\mathrm{h}}, 2 \mathrm{D}_{\mathrm{h}}, 3 \mathrm{D}_{\mathrm{h}}, 4 \mathrm{D}_{\mathrm{h}}, 5 \mathrm{D}_{\mathrm{h}}, 10 \mathrm{D}_{\mathrm{h}}, 15 \mathrm{D}_{\mathrm{h}}$ and $20 \mathrm{D}_{\mathrm{h}}$.

The average velocity (over time), noted $\overline{\mathrm{v}}$, is explored around the central instrumented rod. This measurement region is illustrated by the light blue segments on Fig. 1c.

The Fig. 6 shows the $\bar{v} / V_{\text {flow }}$ dimensionless velocity profiles for $x / D_{h}= \pm 0.54,-1 \leq \mathrm{z} / \mathrm{D}_{\mathrm{h}} \leq 1$ and $z / D_{h}= \pm 0.54,-1 \leq \mathrm{x} / \mathrm{D}_{\mathrm{h}} \leq 1$ and $\mathrm{y} / \mathrm{D}_{\mathrm{h}}$ distances from the grids of $2,3,4,5,10$ and 15 .

The configuration without mixing vanes presents oscillations of the velocity profiles at $y / D_{h}=2$. These oscillations are attributed to the upstream presence of the dimples and spring-blades. With the increase of $y / D_{h}$, the number and the amplitude of these oscillations tend to diminish. Although, the persistence of a main oscillation can be observed.

The configuration with mixing vanes also present some oscillations. Although they tend to be of weaker amplitude than for the configuration without mixing vanes. The number and amplitude of these oscillations decrease with $\mathrm{y} / \mathrm{D}_{\mathrm{h}}$. In addition, apart from $x / D_{h}=0.54$, the persistence of a main oscillation is much less pronounced for the case with mixing vanes than for the case without mixing vanes at $\mathrm{y} / \mathrm{D}_{\mathrm{h}}=15$.

To complement the velocity profiles, the root mean square of the velocity fluctuations, noted $\mathrm{v}_{\mathrm{rms}}^{\prime}$, is quantified. The Fig. 7 gives the dimensionless profiles $\mathrm{v}_{\mathrm{rms}}^{\prime} / \mathrm{V}_{\text {flow }}$ for $x / \mathrm{D}_{\mathrm{h}}= \pm 0.54, \mathrm{z} / \mathrm{D}_{\mathrm{h}}=$ \pm 0.54 , and distances $\mathrm{y} / \mathrm{D}_{\mathrm{h}}$ from the grids equals to $2,3,4,5,10$ and 15 .

Both configurations with and without mixing vanes show oscillations of $\mathrm{v}_{\mathrm{rms}}^{\prime} / \mathrm{V}_{\text {flow }}$ in agreement with the oscillations observed for $\bar{v} / V_{\text {flow }}$. With the increase of the distance from the grid the amplitude of the oscillations and the intensity of $\mathrm{v}_{\mathrm{rms}}^{\prime} / \mathrm{V}_{\text {flow }}$ reduce. The persistence of a main oscillation is also observed. 


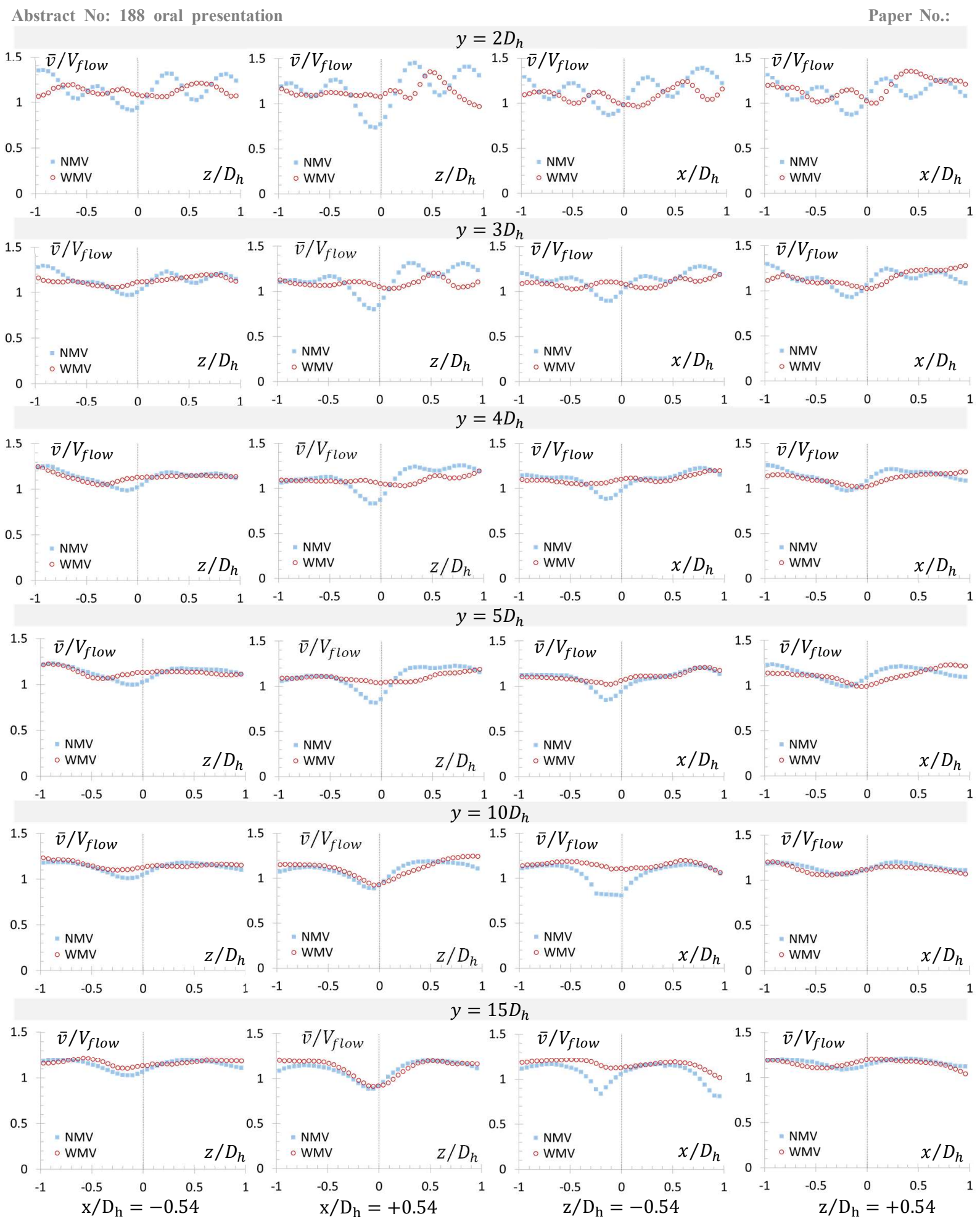

Fig. 6 velocity profiles $\bar{v} / V_{\text {flow }}$ for $x / D_{h}=-0.54, x / D_{h}=+0.54, z / D_{h}=-0.54, z / D_{h}=$ +0.54 (columns from left to right) and $y / D_{h}$ equals to $2,3,4,5,10$ and 15 (rows from top to bottom). 


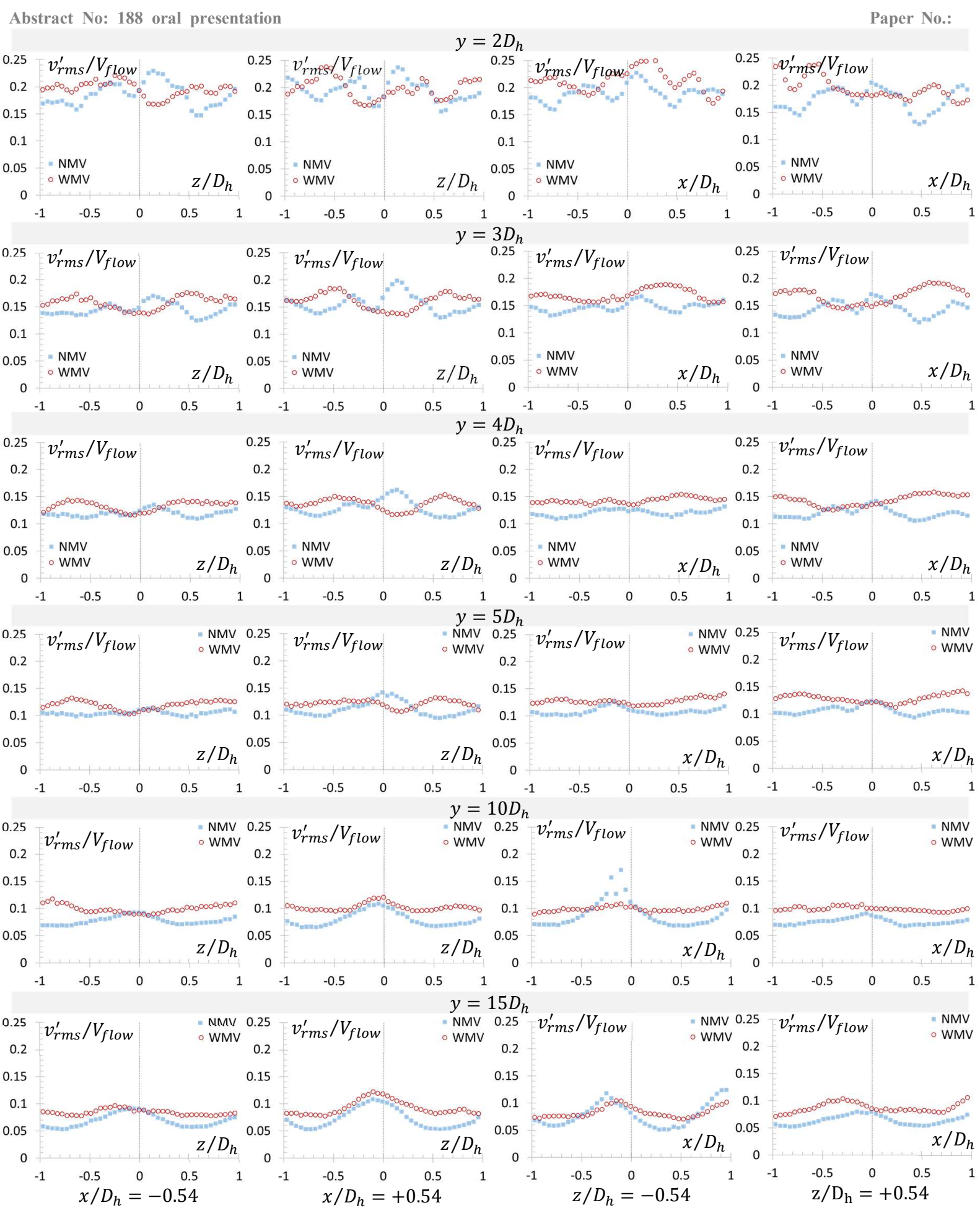

Fig. 7 profiles of the root mean square of velocity fluctuations velocity $v_{\text {rms }}^{\prime} / V_{\text {flow }}$ for $x / D_{h}=$ $-0.54, x / D_{h}=+0.54, z / D_{h}=-0.54, z / D_{h}=+0.54$ (columns from left to right) and $y / D_{h}$ equals to $2,3,4,5,10$ and 15 (rows from top to bottom).

From $y / D_{h}=2$ to $y / D_{h}=15$, the intensity of turbulent fluctuations $\left(\mathrm{v}_{\text {rms }}^{\prime} / \mathrm{V}_{\text {flow }}\right)$ is decreasing from about 0.2 to about 0.08 . The Fig. 8 gives the variations $\left\langle v_{r m s}^{\prime}\right\rangle_{\mathcal{P}_{s q}} / V_{\text {flow }}$ versus $\mathrm{y} / \mathrm{D}_{\mathrm{h}} \cdot\left\langle v_{r m s}^{\prime}\right\rangle_{\mathcal{P}_{s q}}$ is the average of $v_{r m s}^{\prime}$ along $\mathcal{P}_{s q}$ which is the measurement perimeter close to the instrumented rod as illustrated by the blue square on Fig. 1c. Fig. 8 also gives an approximation with power laws and shows trends $\left(y / D_{h}\right)^{-0.38}$ and $\left(y / D_{h}\right)^{-0.46}$ respectively for the configurations with and without mixing vanes. 


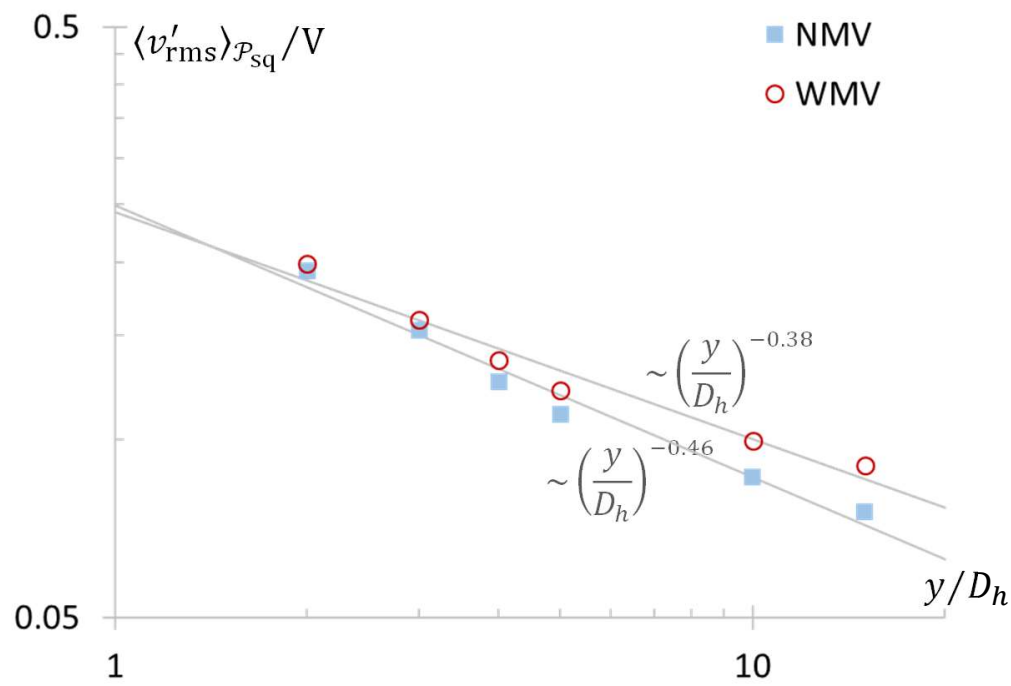

Fig. $8\left\langle v_{r m s}^{\prime}\right\rangle_{\mathcal{P}_{s q}} / V_{\text {flow }}$ for the cases of grids with mixing vanes (WMV) and without mixing vanes (NMV) versus the vertical distance $y / D_{h}$ from the grids. Grey lines indicate power law trends.

The decrease with $y / D_{h}$ of velocity fluctuations is then faster for the configuration without mixing vanes than for the one with mixing vanes. The contrary was observed for pressure fluctuations.

It is interesting to compare the decrease of pressure fluctuations with the decrease of velocity fluctuations versus $y / \mathrm{D}_{\mathrm{h}}$. The dimensionless ratio $\left\langle P_{r m s}^{\prime}\right\rangle_{\theta} / \frac{1}{2} \rho\left\langle v_{r m s}^{\prime}{ }^{2}\right\rangle_{\mathcal{P}_{s q}}$ compares these values. If the pressure fluctuations were strictly related to the velocity fluctuations, one would expect this dimensionless ratio to be about a constant.

Fig. 9 gives $\left\langle P_{r m s}^{\prime}\right\rangle_{\theta} / \frac{1}{2} \rho\left\langle v_{r m s}^{\prime}{ }^{2}\right\rangle_{\mathcal{P}_{s q}}$ versus $y / D_{h}$. The dimensionless ratio $\left\langle P_{r m s}^{\prime}\right\rangle_{\theta} / \frac{1}{2} \rho\left\langle v_{r m s}^{\prime}{ }^{2}\right\rangle_{\mathcal{P}_{s q}}$ is not constant with $y / D_{h}$. Significant increases are observed between $y / D_{h}=2$ and $y / D_{h}=15$. The increases are about $70 \%$ and $100 \%$, respectively for the configurations without and with mixing vanes.

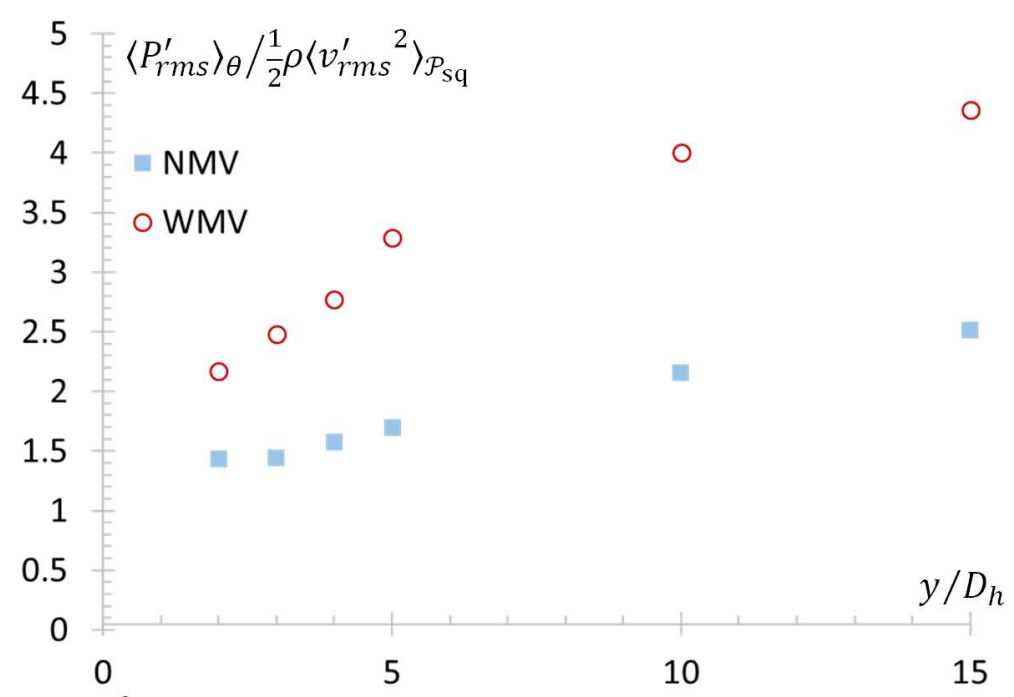

Fig. $9\left\langle P_{r m s}^{\prime}\right\rangle_{\theta} / \frac{1}{2} \rho\left\langle v_{r m s}^{\prime}{ }^{2}\right\rangle_{\mathcal{P}_{s q}}$ for the cases of grids with mixing vanes (WMV) and without mixing vanes (NMV) versus the vertical distance $y / D_{h}$ from the grids.

Such increases of the ratio $\left\langle P_{r m s}^{\prime}\right\rangle_{\theta} / \frac{1}{2} \rho\left\langle v_{r m s}^{\prime}{ }^{2}\right\rangle_{\mathcal{P}_{s q}}$ can be due to the persistence of coherent structures responsible for the main contribution to the pressure fluctuations whilst the non-coherent part of the turbulence generated behind the grids damps more rapidly with $y / D_{h} \cdot\left\langle P_{r m s}^{\prime}\right\rangle_{\theta}$ would be sustained by these persistent pressure structures that can be related to the presence of a peak in the pressure spectra 
of Fig. 5. $\frac{1}{2} \rho\left\langle v_{\text {rms }}^{\prime}{ }^{2}\right\rangle_{\mathcal{P}_{\text {sq }}}$ will be more affected by the damping of the turbulence downstream the grids. To the knowledge of the authors, such quantification and observation are new results. It provides a new insight about the physic of the flow and highlights the possibility to get persisting pressure structures whilst the velocity fluctuations are more affected by the damping of the turbulence downstream the grids with and without mixing vanes.

\section{CONCLUSION}

Pressure fluctuations are explored using an instrumented rod. The orientation of the measurement point and the distance from the grids are varied to explore the flow region surrounding the instrumented rod between $0.5 \mathrm{D}_{\mathrm{h}}$ and $20 \mathrm{D}_{\mathrm{h}}$ downstream the grids. The azimuthal distribution of the pressure fluctuations is then explored for different distances. This shows the non-homogeneity of the pressure fluctuations for both configurations without and with the mixing vanes. It is observed that the return to a homogeneous azimuthal distribution of the pressure fluctuations is faster for the configuration without the mixing vanes than for the configuration with the mixing vanes. Moreover, the intensities of the pressure fluctuations are (in average) higher for the configuration with mixing vanes than for the one without mixing vanes: higher by $13 \%$ and $136 \%$ respectively at distances $0.5 \mathrm{D}_{\mathrm{h}}$ and $20 \mathrm{D}_{\mathrm{h}}$ from the grids. Power law approximations shows decreases of $\left\langle P_{r m s}^{\prime}\right\rangle_{\theta}$ like $\sim\left(y / D_{h}\right)^{-0.46}$ and $\sim\left(y / D_{h}\right)^{-0.68}$ respectively for the configurations with and without mixing vanes.

The profiles of mean velocity and velocity fluctuations are explored around the instrumented rod using LDV. The results show oscillations of the profiles and a damping with the increases of the distance from the grids. Power law approximations show decreases of $\left\langle P_{r m s}^{\prime}\right\rangle_{\theta}$ like $\sim\left(y / D_{h}\right)^{-0.38}$ and $\sim\left(y / D_{h}\right)^{-0.46}$ respectively for the configurations with and without the mixing vanes.

To study the persistence of the pressure fluctuations compared to the velocity fluctuations, $\left\langle P_{r m s}^{\prime}\right\rangle_{\theta} / \frac{1}{2} \rho\left\langle v_{r m s}^{\prime}{ }^{2}\right\rangle_{\mathcal{P}_{s q}}$ is plotted versus $y / D_{h}$. It is shown that this ratio is not constant with significant increases between $2 \mathrm{D}_{\mathrm{h}}$ and $15 \mathrm{D}_{\mathrm{h}}$ : $70 \%$ and $100 \%$ respectively for the configuration without and with mixing vanes. To the knowledge of the authors, this new and original result highlights the complexity of the pressure and turbulent structures in the wake of the grids with and without the mixing vanes.

\section{ACKNOWLEDGMENTS}

The authors wish to thank FRAMATOME and EDF for their support and contribution.

\section{REFERENCES}

[1] U. Bieder, F. Falk and G. Fauchet, "CFD analysis of the flow in the near wake of a generic PWR mixing grid," Annals of Nuclear Energy, vol. 82, pp. 169-178, 2015.

[2] S. Bhattacharjee, G. Ricciardi and S. Viazzo, "Comparative study of the contribution of various PWR spacer grid components to hydrodynamic and wall pressure characteristics," Nuclear Engineering and Design, vol. 317, pp. 22-43, 2017.

[3] S. Delafontaine and G. Ricciardi, "Fluctuating pressure calculation induced by axial flow trough mixing grid," Nuclear Engineering and Design, vol. 242, pp. 233-246, 2012.

[4] K. Ikeda and M. Hoshi, "Development of Rod-embedded Fiber LDV to Measure Velocity in Fuel Rod Bundles," Journal of NUCLEAR SCIENCE and TECHNOLOGY, vol. 43, no. 2, pp. 150-158, 2006.

[5] E. E. Dominguez-Ontiveros and Y. Hassan, "Non-intrusive experimental investigation of flow behavior inside a $5 \times 5$ rod bundle with spacer grids using PIV and MIR," Nuclear Engineering and Design, vol. 239, pp. 888-898, 2009.

[6] F. Moreno, B. Collard and V. Faucher, "Measurement of fluctuating fluid pressure exerted on the walls of a tube bundle," in FIV 2016 11th Conference on Flow-Induced Vibration and Noise, The Hague, The Netherlands, 2016. 